\title{
Editorial
}

\section{Innovation and Development Policy Studies: A New Agenda}

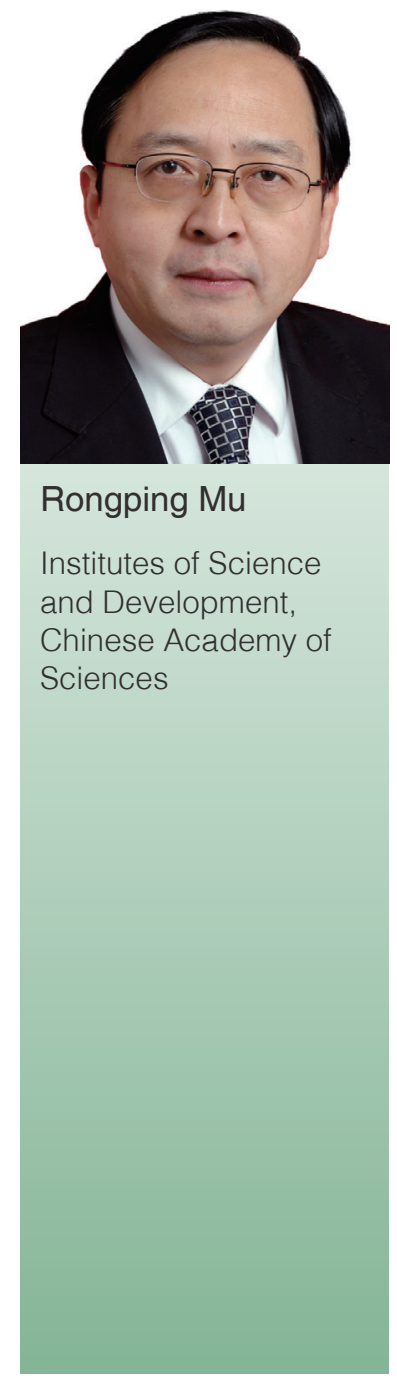

The issues on innovation and development have become increasingly important in the policy-and strategy- making processes of both governments and enterprises, and have received globally growing attention from both policymakers and academia since the 1990s. We are very glad to inform you that the international journal Innovation and Development Policy (IDP) was officially launched in 2018 with support of the China Association for Science and Technology, the Ministry of Education of the People's Republic of China, the Ministry of Finance of the People's Republic of China, the Chinese Academy of Sciences, and etc. We choose IDP as the journal's name because we all believe in the motto "Better policy, better life".

Better policies rely on the better understanding of strategy and management. Therefore, IDP welcomes not only the research on innovation and development policy issues, but also the research on strategy and management issues related to innovationdriven development, embracing the research on theories and methodologies of related issues. IDP publishes original and high-quality papers in English. IDP is an international peerreviewed journal that publishes empirical and theoretical papers in innovation and development policy/management. The journal is devoted to the improvement and further development of the theory and practice of innovation and development policy/ management and designed to appeal to the policy-makers, the practioners and the academics. It publishes original and highquality papers to address the interests of all stakeholders, especially the practicing managers and academic researchers in innovation 
and development policy/management. All IDP papers are expected to yield new findings that have implications for policy/management.

IDP is devoted to building a platform for global innovation and development communications, promoting international academic cooperation and bringing together global intelligence to carry out theoretical, methodological and practical research in innovation and development strategy, policy and management. It is a multi-disciplinary journal that covers the full range of topics in innovation and development policy/management and involves the theory, method and application in innovation and development policy/management. The journal is receptive to all types of quantitative and qualitative methodologies for innovation and development policy. Authors across the world from diverse disciplines and functional perspectives are welcome to contribute to the journal.

In the first issue, the four papers from four different countries or organizations, i.e., China, Japan, Canada and the OECD, display different topics related to innovation and development policy studies, and show their new findings of research, and specific insights based on their long-term observations and experiences. Rongping $\mathrm{Mu}$ et al. from China propose the national innovation development index (NIDI) for a cross-country comparison of innovation development performance, and use the NIDI methodology to investigate 40 countries based on the panel data from 2006 to 2015. Yukihide Hayashi from Japan gives an evolutionary discussion of Japanese Science and Technology Basic Plan from the policy-process perspective, and describes its history, significance, and decision process. Margaret McCuaig-Johnston from Canada presents a long-time track review of Canada-China science and technology collaboration over an 80-year history. Finally, Dominique Guellec and Caroline Paunov from OECD conclude the promoting policies that make innovation benefit all based on discussions of OECD TIP Group @50. They summarize the main takeaways from the TIP@50 meeting, such as: a systemic approach to innovation policy-making is more important than ever; new quantitative methods offer new avenues for evidence-based policy making; getting policy mix for knowledge transfer between industry and science remains a challenge; inclusive innovation policies allow for wider inclusion in innovation processes; and the digitalisation of science and innovation requires changing innovation policies.

In short, we sincerely invite you to share with us your advice for this journal in the future, to contribute or recommend high-quality papers. We hope that IDP together with colleagues around the world will contribute to the sound formulation of national innovation and development policies and strategies in your countries, and to the prosperity of the academic research on innovation and development.

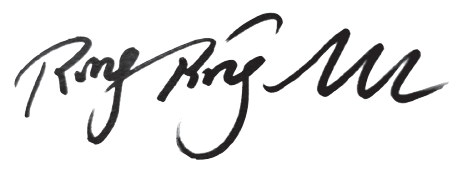

Email: mrp@casipm.ac.cn 